\title{
Estrogen Receptor Is Activated by Korean Red Ginseng In Vitro but Not In Vivo
}

\author{
Myeong Kuk Shim and Young Joo Lee* \\ Department of Bioscience and Biotechnology, Institute of Biotechnology, College of Life Science, Sejong University, Seoul \\ 143-747, Korea
}

Ginseng has been used as a traditional medicine for treatment of many diseases and for general health maintenance in people of all ages. Ginseng is also used to ameliorate menopausal systems. We investigated the estrogenic activity of Korean red ginseng $(\mathrm{KRG})$ in a transient transfection system, using estrogen receptor (ER) and estrogen-responsive luciferase plasmids in MCF-7 cells. The extract activated both ER $\alpha$ and ER $\beta$. KRG modulated the mRNA levels of estrogen-responsive genes such as pS2 and ESR1 and decreased the protein level of ER $\alpha$. In order to examine in vivo estrogenic activity of KRG, sixteen female Sprague-Dawley rats separated into four groups were studied for nine weeks: non-ovariectomized (OVX) rats treated with olive oil, OVX rats treated with olive oil, OVX rats treated with 17- $\beta$-estradiol (E2) in olive oil, and OVX rats treated with KRG extract in olive oil. The experiments were repeated for three times and the data of twelve rats were combined. Body weight of OVX rats was greater than that of sham-operated control rats and was decreased by E2 treatment. Uterine weight increased after E2 treatment compared to OVX rats. However, no difference in body or uterine weight was observed with KRG intake. KRG induced reductions in total cholesterol, low density lipoprotein cholesterol/total cholesterol, high density lipoprotein cholesterol/total cholesterol, and low density lipoprotein cholesterol/high density lipoprotein cholesterol, but not to the same degree as did E2 intake. These results show that KRG does contain estrogenic activity as manifested by in vitro study but the activity is not strong enough to elicit physiological responses.

Keywords: Panax ginseng, Red ginseng, Estrogen receptors, Breast cancer cells, Hypocholesterolemic effects, Menopause

\section{INTRODUCTION}

Ovarian function begins to decrease in women aged between 45 and 54 years. It has been estimated that by the year 2030, over 1.2 billion women will be experiencing menopause. Menopausal symptoms include vasomotor symptoms, including hot flushes and night sweats; central nervous system related symptoms such as insomnia and changes in memory, concentration, and mood; urogenital symptoms including vaginal dryness, urinary tract infections, and urinary urgency; and longterm disease processes including osteoporosis [1-4].

(c) This is an Open Access article distributed under the terms of the Creative Commons Attribution Non-Commercial License (http://creativecommons.org/licenses/by-nc/3.0/) which permits unrestricted non-commercial use, distribution, and reproduction in any medium, provided the original work is properly cited.
Estrogen or combined estrogen and progestin therapy (hormone replacement therapy) is used to alleviate various symptoms associated with diminished ovarian hormone secretion, such as heart disease, osteoporosis, hot flushes, mood swings, night sweats, vaginal dryness, and postmenopausal symptoms [5]. However, the benefit of classical hormone replacement therapy is challenged by the increased risk of cardiovascular disease and breast cancer during and after menopause [6,7]. These concerns have heightened public interest in alternative medicines

\footnotetext{
Received 09 Nov. 2011, Revised 31 Jan. 2012, Accepted 10 Feb. 2012

*Corresponding author

E-mail: yjlee@sejong.ac.kr

Tel: +82-2-3408-3640, Fax: +82-2-3408-4334
} 
as a substitute for pharmacological hormone replacement therapy [8-10]. Studies report on plant-derived estrogenic activity from diverse sources [11-13]. Phytoestrogens are a heterogeneous group of non-steroidal plant-derived compounds that share structural similarities with naturally occurring estrogenic substances, such as $17-\beta$-estradiol (E2) $[14,15]$. Although phytoestrogens are less potent than genuine estrogens, it is surmised that increased concentrations will overcome their comparatively low affinity for the estrogen receptor (ER). Ginseng has been used to treat cancer, diabetes, and cardiovascular diseases $[16,17]$. In US, ginseng is one of the herbs used to alleviate menopausal symptoms along with black cohosh [18]. However, recent data suggested that black cohosh may increase mammary cancer [19]. In contrast, the antitumor activity of ginseng has been shown in numerous experimental systems [20]. In addition, several reports demonstrated that ginseng extracts and ginsenosides stimulate estrogen signaling via both direct and indirect effects [18,21]. However, clinical trials using ginseng extracts did not prove real efficacy as an estrogen-replacement therapy [18] indicating that more accumulating extensive both in vitro and in vivo data are needed to adequately evaluate this activity. In this study, we investigated the ER $\alpha$ and ER $\beta$-mediated effects of Korean red ginseng (KRG) extracts in in vitro. In addition, we evaluated estrogenic effects in ovariectomized (OVX) rats, as compared to exogenously administered E2.

\section{MATERIALS AND METHODS}

\section{Cell culture and reagent}

MCF-7 cells were grown at $37^{\circ} \mathrm{C}$ in a humidified atmosphere of $95 \%$ air $/ 5 \% \mathrm{CO}_{2}$ in phenol red-free RPMI 1640 medium supplemented with $10 \%$ fetal bovine serum (FBS) (Welgene, Daegu, Korea). Before treatment, the cells were washed with phosphate-buffered saline and cultured in RPMI $/ 5 \%$ charcoal-dextran stripped FBS for $1 \mathrm{~d}$ to eliminate any estrogenic source before treatment. E2 was purchased from Sigma (St. Louis, MO, USA) and dissolved in $100 \%$ ethanol. ICI 182,780 (ICI) was obtained from Zeneca Pharmaceuticals (Tocris, UK). Water extract from 6-year-old KRG extract was donated by Central Research Institute, Korea Ginseng Corporation (Daejeon, Korea). The extracts were dissolved in distilled water at the concentration of 0.1 and $0.5 \mathrm{mg} / \mathrm{mL}$.

\section{Plasmids}

The ERE-tk81-luc, constructed by inserting the fragment of the herpes simplex thymidine kinase promoter and two copies of the vitellogenin estrogen response element (ERE) into pA3luc was a gift from Dr. Larry Jameson [22], expression vetors for ER $\alpha$ was received from Dr. Pierre Chambon [23]. The hER $\beta$ expression vector was kindly provided by Dr. Mesut Muyan [24].

\section{Transient transfection and luciferase assay}

MCF-7 cells were transiently transfected with plasmids by using the polyethylenimine (Polysciences, Warrington, PA, USA). Luciferase activity was determined $24 \mathrm{~h}$ after treatment with a Lumat LB9507 luminometer using the luciferase assay system and expressed as relative light units.

\section{Immunoblot analysis}

Protein was separated using a radioimmune precipitation buffer (including $150 \mathrm{mM} \mathrm{NaCl}, 50 \mathrm{mM}$ Tris- $\mathrm{HCl}$, $1 \%$ NP- $40,0.5 \%$ deoxycholic acid and $0.1 \%$ sodium dodecyl sulfate (SDS), with a protease inhibitor cocktail) on ice for $1 \mathrm{~h}$ and then centrifuged for $25 \mathrm{~min}$ at 13,000 rpm. Protein concentrations were determined using the Bradford method (Bio-Rad, Hercules, CA, USA). For immunoblotting, proteins were separated by SDS-polyacrylamide gel electrophoresis (PAGE) and electro-transferred to polyvinylidene fluoride membrane as previously described. Subsequently, the membranes were blocked with $5 \%$ non-fat dry milk in tris-buffered saline (TBS) containing $0.05 \%(\mathrm{v} / \mathrm{v})$ Tween 20 for $1 \mathrm{~h}$ at room temperature, washed $3 \times 5$ min with TBS and incubated with anti-rabbit polyclonal antibody to ER $\alpha$ diluted 1:1,000 in TBS containing $0.05 \%$ (v/v) Tween 20 at $4{ }^{\circ} \mathrm{C}$ for $16 \mathrm{~h}$. (Santa Cruz Biotechnology Inc., Santa Cruz, CA, USA) or anti-mouse polyclonal antibody to $\beta$-actin diluted 1:4,000 (Sigma). The blot was washed $3 \times 5$ min with TBS (0.05\% Tween 20$)$, blots were incubated with goat anti-rabbit (Invitrogen, Carlsbad, CA, USA; dilution 1:2,500) or anti-mouse (Invitrogen, dilution 1:5,000) horseradish peroxidase-confugated secondary antibody and visualized with enhanced chemiluminescence ECL kits (Amersham Bioscience, Little Chalfont, UK).

\section{Vascular endothelial growth factor enzyme-linked immunosorbent assay}

MCF-7 cells were seeded in 24 well plates and treated with 0.1 or $0.5 \mathrm{mg} / \mathrm{mL} \mathrm{KRG} \mathrm{extracts} \mathrm{for} 24 \mathrm{~h}$. The culture medium was removed and stored at $-80^{\circ} \mathrm{C}$ until assayed. Vascular endothelial growth factor (VEGF) concentration was determined using enzyme-linked immunosorbent assay (ELISA) kit (R\&D Systems, Minneapolis, MN, USA) according to the manufacturer's in- 
structions. Sample from two different experiments were analyzed in triplicate.

\section{Real-time reverse transcription polymerase chain reaction}

MCF-7 cells were treated with $10 \mathrm{nM} \mathrm{E} 2$ or $0.5 \mathrm{mg} /$ $\mathrm{mL} \mathrm{KRG}$ in the presence or absence of $1 \mu \mathrm{M}$ ICI for 24 h. After $24 \mathrm{~h}$ of treatment, total RNA was isolated from cells by using Trizol reagent according to the standard protocol. RNA pellets were dissolved in diethylpyrocarbonate-treated water. The yield of RNA was quantified by spectroscopy at $260 \mathrm{~nm}$. To synthesis first cDNA, 3 $\mu \mathrm{g}$ total RNA was incubated at $70^{\circ} \mathrm{C}$ for 5 min with 0.5 $\mu \mathrm{L}$ of random hexamer and deionized water (up to 11.5 $\mu \mathrm{L}$ ). The reverse transcription reaction was performed using $4 \mu \mathrm{L}$ of M-MLV reverse transcription $5 \mathrm{X}$ buffer, $0.5 \mu \mathrm{L}$ of M-MLV reverse transcriptase, $4 \mu \mathrm{L}$ of $2.5 \mathrm{mM}$ dNTP mixtures at $37^{\circ} \mathrm{C}$ for $60 \mathrm{~min}$. The reaction was terminated by heating at $70^{\circ} \mathrm{C}$ for $10 \mathrm{~min}$. The sequences of the PCR primer for ESR1, pS2 and $\beta$-actin (Genotech, Daejeon, Korea) were: ESR1 primer, 5'-CCA TGT GGC AGA TCC CAC AGG AGT T-3', antisense primer, 5'TCC AAA TTC AAC ACT CAG TGC CCG G-3'; pS2 primer, 5'-CAT GGA GAA CAA GGT GAT CTG-3', antisense primer 5'-CAG AAG CGT GTC TGA GGT GTC-3'; $\beta$-actin primer, 5'-CAT GGA GAA CAA GGT GAT CTG-3', antisense primer 5'-CAG AAG CGT GTC TGA GGT GTC-3'. PCR was carried out in $25 \mu \mathrm{L}$ reaction mixture containing $8 \mu$ iQ SYBR green superrmix (Bio-Rad) and $0.9 \mu \mathrm{L}$ of cDNA template. Real-time PCR system (Bio-Rad) using the following cycle parameters: 1 cycle of $95^{\circ} \mathrm{C}$ for $5 \mathrm{~min}$, and 40 cycles of $94^{\circ} \mathrm{C}$ for 30 $\mathrm{s}, 55^{\circ} \mathrm{C}$ for $30 \mathrm{~s}$, and $72^{\circ} \mathrm{C}$ for $30 \mathrm{~s}$. The target gene transcripts in each sample were normalized on the basis of its $\beta$-actin.

\section{Animals and treatment}

Nine-weeks-old female Sprague-Dawley rats $(210 \pm 5$ g) were purchased from Samtako (Osan, Korea) and stabilized for two weeks. At the end of the 5 weeks experimental period, animals were 16 weeks old. The animals were kept at a temperature of $23 \pm 2^{\circ} \mathrm{C}$ with a $12 \mathrm{~h}$ light and dark cycle and allowed free access to food and water. The study was carried out on four groups of animal each consisted of four rats, repeated for three times, and presented with the combined results from three experiments total of twelve rats. Three groups of rats were OVX and one group of rats was used as a sham group. For 5 wk every dayly, rats were orally injected with E2 $(0.5 \mathrm{mg} /$ $\mathrm{kg}$, in $1 \mathrm{~mL}$ olive oil), $\mathrm{KRG}(0.2 \mathrm{~g}$, in $1 \mathrm{~mL}$ olive oil $)$ or olive oil as a control. Group 1 non OVX rats were shamoperated. The uteri were dissected out to measure their weight and used to show the estrogenic hypertrophy. Rats were anesthetized with ether and blood was obtained from the abdominal aorta. Serum cholesterol, highdensity lipoprotein (HDL) and low-density lipoprotein (LDL) concentrations were determined at Seoul Clinical Laboratories (Seoul, Korea).

\section{Statistical analysis}

Values shown represent mean \pm SD. Statistical analysis was performed by Student's $t$-test with a $p$-value of less than 0.05 being considered statistically significant. Statistical significance between experimental groups was analyzed by ANOVA and the significance level was set at $p<0.05$.

\section{RESULTS AND DISCUSSION}

\section{Korean red ginseng activates estrogen receptor $a$ and estrogen receptor $\beta$ in MCF-7 cells}

The biological activities of estrogen are mediated by two distinct receptors, ER $\alpha$ and ER $\beta$. The activation of ER is initiated by ligand binding followed by dimerization of receptors and DNA binding, resulting in transcriptional activation [25-27]. Proper ligand binding to ER initiates transcriptional activation through the specific EREs in target genes [28]. We examined whether KRG activates the transcription of EREs containing a receptor plasmid in MCF-7 cells. To evaluate the effects of E2 and KRG on ER $\alpha$ - and ER $\beta$-mediated transcription, MCF-7 cells were transfected with either ER $\alpha$ or ER $\beta$ and ERE-luciferase and treated with E2 and KRG for $24 \mathrm{~h}$. Both E2 and $0.5 \mathrm{mg} / \mathrm{mL} \mathrm{KRG}$ induced luciferase activity in MCF-7 cells through ER $\alpha$ (Fig. 1A) and ER $\beta$ (Fig. 1B).

\section{Induction of endogenous estrogen-responsive genes in MCF-7 cells}

To evaluate the potential of KRG as a modulator of estrogen-responsive genes, we examined induction of pS2 and ESR1 at the mRNA level by real-time RT-PCR analysis (Fig. 2). The mRNA levels of these genes at 24 $\mathrm{h}$ were regulated by KRG in a similar manner as E2 (Fig. 2). To confirm that the activities of KRG were ER mediated, cells were co-treated with the pure anti-estrogen ICI, at a concentration sufficient to saturate almost all the ERs in the cells $(1 \mu \mathrm{M})$. Co-incubation with ICI efficiently blocked the activation of ESR1 and pS2 mRNA expression, indicating activation through ER (Fig. 2). E2 

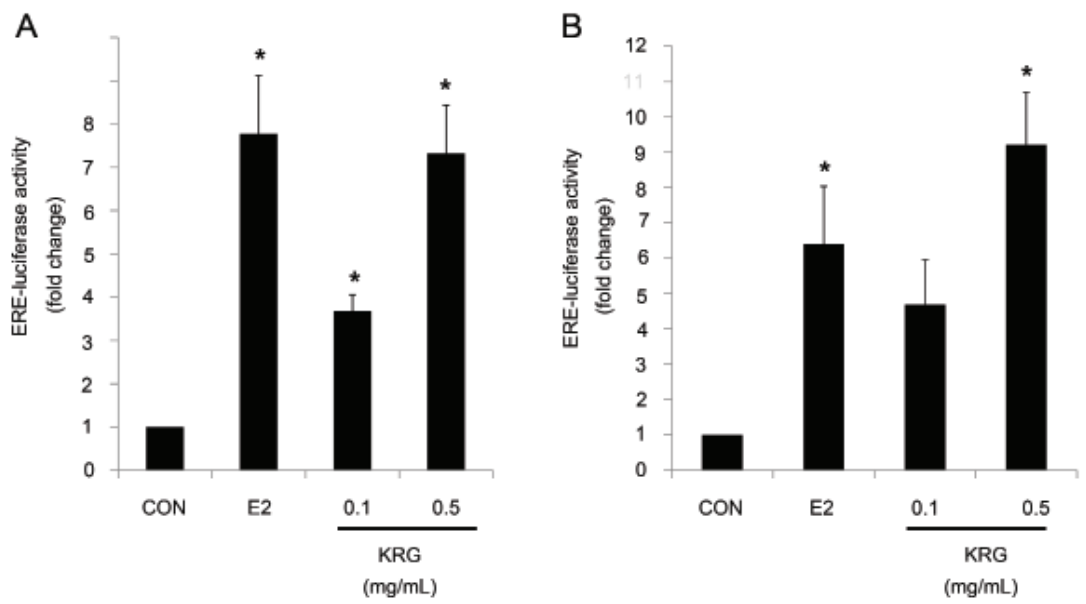

Fig. 1. Activation of estrogen receptor (ER) by Korean red ginseng (KRG) in MCF-7 cells. Cells were transiently transfected with estrogen response element (ERE)-luciferase reporter plasmid and either $h E R \alpha(A)$ or $h E R \beta(B)$ expression plasmid. Cells were treated with $10 \mathrm{nM}$ $17 \beta$-estradiol (E2) or $0.1,0.5 \mathrm{mg} / \mathrm{mL}$ KRG for $24 \mathrm{~h}$ followed by transient transfection. Cell lysates were prepared and analyzed by luciferase assays. The data are representative of at least three independent experiments performed in triplicate. CON, control.

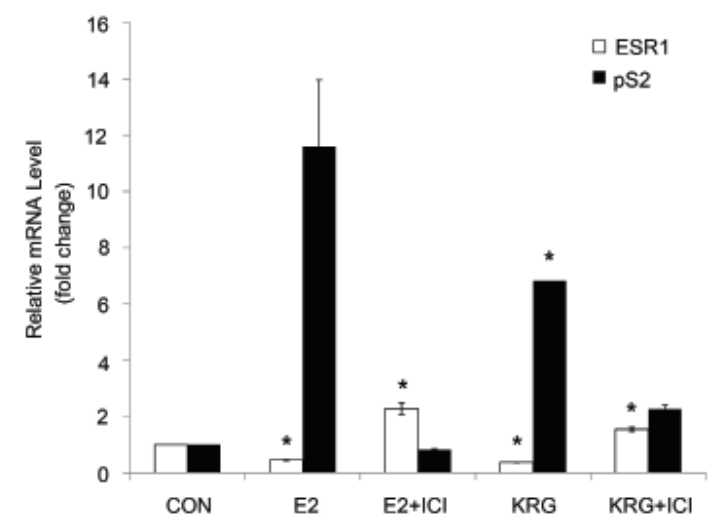

Fig. 2. Effects of Korean red ginseng (KRG) on endogenous estrogen-responsive ESR1 and pS2 mRNA levels were examined. Cells were exposed to $10 \mathrm{nM} 17 \beta$-estradiol (E2) or $0.1,0.5 \mathrm{mg} / \mathrm{mL}$ KRG with or without $1 \mu \mathrm{M} \mathrm{ICl} 182,780$ (ICl) as indicated for $24 \mathrm{~h}$. The quantitative reverse transcriptase polymerase chain reaction results for ESR1, pS2 in MCF-7 cells are shown. CON, control.

induces down-regulation of ERs after as little as $30 \mathrm{~min}$ in E2-responsive cells [29,30]. To evaluate the effect of KRG on ER $\alpha$ protein down-regulation in MCF-7 cells, whole-cell protein extracts were prepared and the ER $\alpha$ level was determined by Western blotting. ER protein levels were down-regulated by treatment with E2 or 0.5 $\mathrm{mg} / \mathrm{mL}$ KRG as compared with the vehicle control (Fig. 3A). As known, ICI further downregulated ER $\alpha$ either with E2 or KRG treatment. To further confirm in vitro estrogenic activity of KRG, VEGF secretion was measured in MCF-7 cells as by ELISA (Fig. 3B). Both E2 and KRG enhanced VEGF secretion (Fig. 3B).

\section{Effect of Korean red ginseng on body and uterine weight and serum cholesterol levels in ovariecto- mized rats}

We determined the estrogenic activity of $\mathrm{KRG}$ in vivo using OVX rats as a model system [31]. Body weight gain was significantly increased in OVX animals compared to the sham-operated control group after $5 \mathrm{wk}$ of olive oil vehicle treatment (Fig. 4A). As expected, E2 treatment significantly lowered body weight gain to approximately the level of sham controls. Uterine weight in the OVX control rats was significantly decreased compared with sham controls, and E2-injection maintained a uterine weight comparable to that of the sham controls (Fig. 4B). KRG treatment did not increase uterine weight in contrast to E2 (Fig. 4B).

It is generally agreed that higher HDL and lower LDL concentrations benefit the chemoprevention of cardiovascular diseases [32]. Some reports have indicated that soybean isoflavones may prevent coronary heart disease and hyperlipidemia and atherosclerosis [33]. Forsythe reported that reduction of serum cholesterol concentration by phytoestrogen may be achieved by increasing the metabolic rate of LDL and very-LDL [34]. Szkudelska et al. [35] demonstrated that supplementation with $0.1 \%$ genistein for $14 \mathrm{~d}$ effectively reduced serum cholesterol levels and lipid synthesis of OVX rats and LDL binding to its receptor. Reduced serum cholesterol and lipid biosynthesis may consequently decrease LDL-cholesterol levels and increase HDL-cholesterol levels. To this end, we hypothesized that KRG intake may improve lipoprotein parameters acting as phytoestrogen in agree- 
A

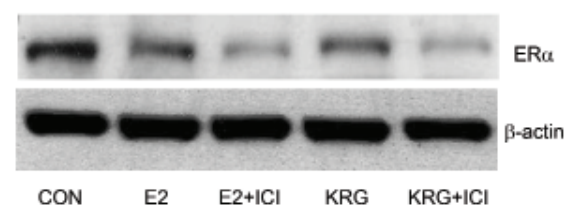

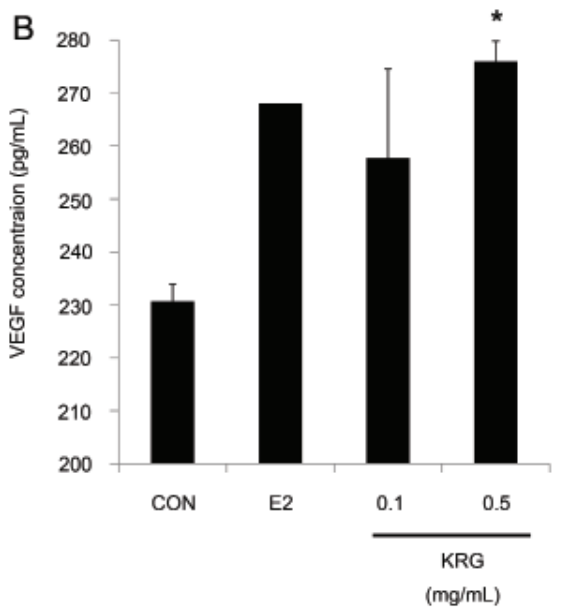

Fig. 3. MCF-7 cells were treated for $24 \mathrm{~h}$ with $10 \mathrm{nM} 17 \beta$-estradiol (E2) or $0.1,0.5 \mathrm{mg} / \mathrm{mL}$ Korean red ginseng (KRG) with or without $1 \mu \mathrm{M} I \mathrm{Cl}$ $182,780(\mathrm{ICl})$ as shown $(\mathrm{A})$. An untreated group served as a control. After the incubation, the cells were lysed and total protein extracts were resolved by sodium dodecyl sulfate-polyacrylamide gel electrophoresis and immunoblotted using an anti-estrogen receptor (ER) antibody or an anti- $\beta$-actin antibody. MCF-7 cells were treated as indicated and vascular endothelial growth factor (VEGF) protein level was measured by enzyme-linked immunosorbent assay form the cell culture supernatant (B). The asterisk shows a statistically significant difference from control (CON) group at $p<0.05$.
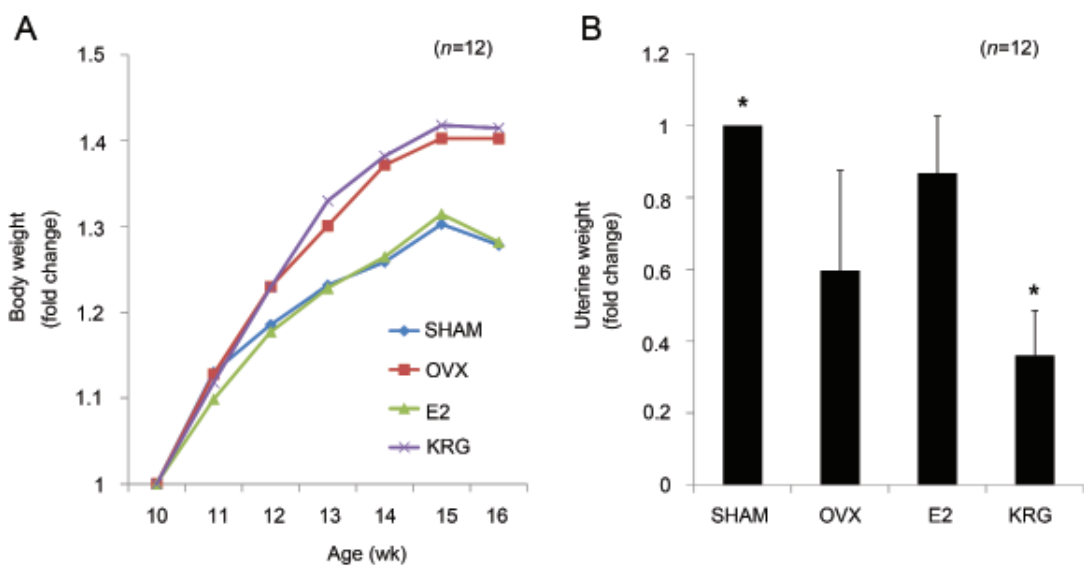

Fig. 4. Effect of Korean red ginseng (KRG) on body weight and uterine weight of ovariectomized (OVX) rats. Treatment groups are: SHAM, sham operated group; OVX, OVX groups treated olive oil; $17-\beta$-estradiol (E2), OVX groups treated olive oil-estradiol; KRG, OVX groups treated olive oil-KRG. The asterisk shows a statistically significant difference from control group at $p<0.05$.

ment with our in vitro results. The effects of KRG on the changes in total cholesterol (TC) are shown in Table 1. OVX controls exhibited substantial increases in TC and LDL levels compared to sham controls. E2 injection significantly decreased TC and LDL compared with OVX controls to the level of the sham controls. KRG treatment caused considerable reductions in serum cholesterol and decreases in both HDL and LDL; however, this was not statistically significant. KRG treatment also reduced atherogenic indices and the HDL/TC ratio, but no statistical difference was observed when compared to OVX controls. In conclusion, KRG exhibited protective effects on cardiovascular parameters. Although these effects are not proven to be through the ER signaling pathway because
Table 1. Hypocholesterolemic effect of KRG in OVX adult female rats

\begin{tabular}{lcccc}
\hline & SHAM $(n=12)$ & OVX $(n=12)$ & E2 $(n=12)$ & KRG $(n=12)$ \\
\hline TC $(\mathrm{mg} / \mathrm{dL})$ & $79.42 \pm 11.69^{*}$ & $105.67 \pm 22.42$ & $92.83 \pm 20.51$ & $92.67 \pm 12.61$ \\
HDL mg/dL) & $27.42 \pm 5.69^{*}$ & $32.67 \pm 5.84$ & $30.42 \pm 6.61$ & $28.33 \pm 3.37 *$ \\
LDL (mg/dL) & $6.67 \pm 0.75 *$ & $10.50 \pm 3.18$ & $6.75 \pm 2.01 *$ & $8.67 \pm 1.55$ \\
HDL/TC & $0.34 \pm 0.04$ & $0.32 \pm 0.06$ & $0.33 \pm 0.03$ & $0.31 \pm 0.03$ \\
LDL/TC & $0.09 \pm 0.01 *$ & $011 \pm 003$ & $007 \pm 002 *$ & $009 \pm 001$ \\
LDL/HDL & $0.25 \pm 0.06 *$ & $0.35 \pm 0.13$ & $0.23 \pm 0.10^{*}$ & $0.31 \pm 0.04$
\end{tabular}

KRG, Korean red ginseng; OVX, ovariectomized; TC, total cholesterol; HDL, high-density lipoprotein; LDL, low density lipoprotein. ${ }^{*} p<0.05$.

KRG did not induce changes in body weight and uterine weight as did E2, our results indicates that KRG intake 
has beneficial cholesterol-reducing effects on to menopausal women.

\section{ACKNOWLEDGEMENTS}

This work supported by the 2009 grant from the Korean Society of Ginseng funded by the Korea Ginseng Corporation.

\section{REFERENCES}

1. Doyle BJ, Frasor J, Bellows LE, Locklear TD, Perez A, Gomez-Laurito J, Mahady GB. Estrogenic effects of herbal medicines from Costa Rica used for the management of menopausal symptoms. Menopause 2009;16:748755 .

2. Lissin LW, Cooke JP. Phytoestrogens and cardiovascular health. J Am Coll Cardiol 2000;35:1403-1410.

3. Kallen AN, Pal L. Cardiovascular disease and ovarian function. Curr Opin Obstet Gynecol 2011;23:258-267.

4. Yanes LL, Reckelhoff JF. Postmenopausal hypertension. Am J Hypertens 2011;24:740-749.

5. King J, Wynne CH, Assersohn L, Jones A. Hormone replacement therapy and women with premature menopause--a cancer survivorship issue. Eur J Cancer 2011;47:1623-1632.

6. Rossouw JE, Anderson GL, Prentice RL, LaCroix AZ, Kooperberg C, Stefanick ML, Jackson RD, Beresford SA, Howard BV, Johnson KC et al. Risks and benefits of estrogen plus progestin in healthy postmenopausal women: principal results from the Women's Health Initiative randomized controlled trial. JAMA 2002;288:321-333.

7. Anderson GL, Limacher M, Assaf AR, Bassford T, Beresford SA, Black H, Bonds D, Brunner R, Brzyski $\mathrm{R}$, Caan B et al. Effects of conjugated equine estrogen in postmenopausal women with hysterectomy: the Women's Health Initiative randomized controlled trial. JAMA 2004;291:1701-1712.

8. This P, de Cremoux P, Leclercq G, Jacquot Y. A critical view of the effects of phytoestrogens on hot flashes and breast cancer risk. Maturitas 2011;70:222-226.

9. Zhao L, Mao Z, Brinton RD. A select combination of clinically relevant phytoestrogens enhances estrogen receptor beta-binding selectivity and neuroprotective activities in vitro and in vivo. Endocrinology 2009;150:770-783.

10. Zhao E, Mu Q. Phytoestrogen biological actions on Mammalian reproductive system and cancer growth. Sci Pharm 2011;79:1-20.

11. Xin D, Wang H, Yang J, Su YF, Fan GW, Wang YF, Zhu Y, Gao XM. Phytoestrogens from Psoralea corylifolia re- veal estrogen receptor-subtype selectivity. Phytomedicine 2010;17:126-131.

12. Bolle P, Mastrangelo S, Perrone F, Evandri MG. Estrogen-like effect of a Cimicifuga racemosa extract subfraction as assessed by in vivo, ex vivo and in vitro assays. J Steroid Biochem Mol Biol 2007;107:262-269.

13. Simoncini T, Lenzi E, Zochling A, Gopal S, Goglia L, Russo E, Polak K, Casarosa E, Jungbauer A, Genazzani $\mathrm{AD}$ et al. Estrogen-like effects of wine extracts on nitric oxide synthesis in human endothelial cells. Maturitas 2011;70:169-175.

14. Cos P, De Bruyne T, Apers S, Vanden Berghe D, Pieters L, Vlietinck AJ. Phytoestrogens: recent developments. Planta Med 2003;69:589-599.

15. Sunita P, Pattanayak SP. Phytoestrogens in postmenopausal indications: a theoretical perspective. Pharmacogn Rev 2011;5:41-47.

16. Kwak YS, Kyung JS, Kim JS, Cho JY, Rhee MH. Antihyperlipidemic effects of red ginseng acidic polysaccharide from Korean red ginseng. Biol Pharm Bull 2010;33:468-472.

17. Min SW, Jung SH, Cho KH, Kim DH. Antihyperlipidemic effects of red ginseng, crataegii fructus and their main constituents ginsenoside $\mathrm{Rg}_{3}$ and ursolic acid in mice. Biomol Ther 2008;16:364-369.

18. Cho J, Park W, Lee S, Ahn W, Lee Y. Ginsenoside-Rb from Panax ginseng C.A. Meyer activates estrogen receptor-alpha and -beta, independent of ligand binding. J Clin Endocrinol Metab 2004;89:3510-3515.

19. Davis VL, Jayo MJ, Ho A, Kotlarczyk MP, Hardy ML, Foster WG, Hughes CL. Black cohosh increases metastatic mammary cancer in transgenic mice expressing cerbB2. Cancer Res 2008;68:8377-8383.

20. Jeon C, Kang S, Park S, Lim K, Hwang KW, Min H. T Cell stimulatory effects of Korean red ginseng though modulation of myeloid-derived suppressor cells. J Ginseng Res 2011;35:462-470.

21. Lau WS, Chen WF, Chan RY, Guo DA, Wong MS. Mitogen-activated protein kinase (MAPK) pathway mediates the oestrogen-like activities of ginsenoside $\mathrm{Rg}_{1}$ in human breast cancer (MCF-7) cells. Br J Pharmacol 2009; 156:1136-1146.

22. Gehm BD, McAndrews JM, Chien PY, Jameson JL. Resveratrol, a polyphenolic compound found in grapes and wine, is an agonist for the estrogen receptor. Proc Natl Acad Sci U S A 1997;94:14138-14143.

23. Chen D, Lucey MJ, Phoenix F, Lopez-Garcia J, Hart SM, Losson R, Buluwela L, Coombes RC, Chambon P, Schar $\mathrm{P}$ et al. T:G mismatch-specific thymine-DNA glycosylase potentiates transcription of estrogen-regulated genes 
through direct interaction with estrogen receptor alpha. J Biol Chem 2003;278:38586-38592.

24. Li X, Huang J, Yi P, Bambara RA, Hilf R, Muyan M. Single-chain estrogen receptors (ERs) reveal that the ERalpha/beta heterodimer emulates functions of the ERalpha dimer in genomic estrogen signaling pathways. Mol Cell Biol 2004;24:7681-7694.

25. La Rosa P, Acconcia F. Signaling functions of ubiquitin in the 17 $\beta$-estradiol (E2):estrogen receptor (ER) $\alpha$ network. J Steroid Biochem Mol Biol 2011;127:223-230.

26. McDevitt MA, Glidewell-Kenney C, Jimenez MA, Ahearn PC, Weiss J, Jameson JL, Levine JE. New insights into the classical and non-classical actions of estrogen: evidence from estrogen receptor knock-out and knock-in mice. Mol Cell Endocrinol 2008;290:24-30.

27. Barros RP, Gustafsson JA. Estrogen receptors and the metabolic network. Cell Metab 2011;14:289-299.

28. Gehm BD, McAndrews JM, Jordan VC, Jameson JL. EGF activates highly selective estrogen-responsive reporter plasmids by an ER-independent pathway. Mol Cell Endocrinol 2000;159:53-62.

29. Cho J, Kim D, Lee S, Lee Y. Cobalt chloride-induced estrogen receptor alpha down-regulation involves hypoxiainducible factor-1alpha in MCF-7 human breast cancer cells. Mol Endocrinol 2005;19:1191-1199.

30. Valley CC, Solodin NM, Powers GL, Ellison SJ, Alarid ET. Temporal variation in estrogen receptor-alpha protein turnover in the presence of estrogen. J Mol Endocrinol 2008;40:23-34.

31. Henley DV, Korach KS. Physiological effects and mechanisms of action of endocrine disrupting chemicals that alter estrogen signaling. Hormones (Athens) 2010;9:191205.

32. Kim EY, Baek IH, Rhyu MR. Cardioprotective effects of aqueous Schizandra chinensis fruit extract on ovariectomized and balloon-induced carotid artery injury rat models: effects on serum lipid profiles and blood pressure. J Ethnopharmacol 2011;134:668-675.

33. Wangen KE, Duncan AM, Xu X, Kurzer MS. Soy isoflavones improve plasma lipids in normocholesterolemic and mildly hypercholesterolemic postmenopausal women. Am J Clin Nutr 2001;73:225-231.

34. Forsythe WA, Green MS, Anderson JJ. Dietary protein effects on cholesterol and lipoprotein concentrations: a review. J Am Coll Nutr 1986;5:533-549.

35. Szkudelska K, Nogowski L. Genistein: a dietary compound inducing hormonal and metabolic changes. J Steroid Biochem Mol Biol 2007;105:37-45. 